\title{
Os Centros Históricos como laboratórios de Educação Histórica e Patrimonial
}

Historic Centres as laboratories of History and Heritage Education

Helena Pinto*

\section{RESUmo}

O desenvolvimento, de forma sistemática e segundo critérios metodológicos, de atividades educativas relacionadas com património carece de discussão sobre práticas consistentes de Educação Patrimonial em articulação com reflexão sobre pesquisa existente em Educação Histórica. A par da sensibilização para a salvaguarda do património, os professores podem realizar práticas promovendo a interpretação de fontes diversas - nomeadamente objetos em contexto de centros históricos - encorajando os alunos a questioná-las de forma crítica e progressivamente mais complexa. Apresenta-se um estudo de natureza qualitativa, que investigou como alunos portugueses (de $7^{\circ}$ e $10^{\circ}$ ano) inferem a partir de objetos/edifícios durante um percurso no centro histórico de Guimarães, Portugal, em atividade educativa, com seus professores de História. A análise de dados sugeriu diver-

\section{Abstract}

The development under systematic and methodological criteria, of educational activities related to the use of heritage sources, demands a discussion about consistent heritage education practices, combining it with a reflection on existing history education research. Along with an attentiveness on heritage preservation, teachers can implement a variety of practices to promote interpretation of different sources - namely the use of objects within historic centres context- encouraging students to question them critically and of an increasingly complex way. We present here a study of qualitative nature, which sought to investigate how Portuguese students (from $7^{\text {th }}$ and $10^{\text {th }}$ grades) infer from objects and buildings along a walk through the historic centre of Guimarães (Portugal) during educational activities with their history teachers. Data analysis suggested various concep-

\footnotetext{
* Doutora em Ciências da Educação - Especialidade de Educação em História e Ciências Sociais, Universidade do Minho, Portugal. Investigadora Integrada do Centro de Investigação Transdisciplinar "Cultura, Espaço e Memória" (CITCEM). Grupo de Investigação "Memória, Património e Construção de Identidades”, Faculdade de Letras da Universidade do Porto (FLUP). Porto, Portugal.mhelenapinto@gmail.com
} 
sos perfis conceptuais quanto ao modo como os alunos dão sentido ao património, e como eles e seus professores entendem a relação dialógica entre passado, presente e futuro, que caracteriza a consciência histórica.

Palavras-chave: educação histórica; educação patrimonial; consciência patrimonial; consciência histórica. tual profiles concerning how students make sense of heritage, and how they and their teachers recognize the dialogic relationship between past, present and future that characterizes Historical Consciousness.

Keywords: History education; heritage education; heritage awareness; historical consciousness.

\section{Centros Históricos E construção do Património}

A característica que mais sobressai da reflexão sobre o conceito de património é a temporalidade. O património espelha os vários tempos; é expressão de uma comunidade, da sua cultura, nas suas especificidades e convergências, sendo por isso um fator identitário e, muitas vezes, lugar de escolhas apaixonadas e de conflitos (Le Goff, 1998).

A ligação entre a problemática da identidade e a do património - à escala da identidade nacional e do património cultural - ressalta da tomada de consciência de que ambas se organizaram em torno da questão das relações com o lugar e com o tempo. Monumento, cidade histórica e património cultural são noções relacionadas com o modo como as sociedades ocidentais assumiram a sua relação com a temporalidade e construíram as suas identidades.

Terão sido a entrada na Era Industrial e o sentimento de nostalgia de uma perda irreparável que criaram face ao monumento histórico a mediação e distância consecutivas, ao mesmo tempo que impulsionavam a sua proteção (Choay, 2000). Pequenas cidades ainda quase intactas tornavam-se "vestígios frágeis e preciosos de um estilo de vida original, de uma cultura em vias de extinção, a proteger incondicionalmente e, no limite, a classificar como reserva ou a musealizar" (ibidem, p.168). Pouco a pouco, e sobretudo durante o século $\mathrm{XX}$, verificou-se uma tripla extensão - tipológica, cronológica e geográfica dos bens patrimoniais. Uma série de cartas e convenções internacionais têm coordenado este movimento e embora ainda se verifique alguma distância entre os princípios e o seu respeito, temos assistido a um crescente interesse pelo património, pela sua preservação e divulgação. Esta atenção, centrada inicialmente nos monumentos de maior significado histórico, alargou-se a 
novas abordagens culturais e ambientalistas, tentando contrariar as agressões provocadas pelas mudanças urbanísticas, mas também ao intangível. Por outro lado, a par da mundialização do património, reforçou-se a proteção a nível nacional e local, revelando a necessidade de uma filiação, de encontrar traços distintivos, as identidades. O património tornou-se assunto dominante na vida cultural e nas políticas públicas. Procedeu-se ao inventário de novos 'patrimónios' e estabeleceram-se novos usos do património. As Jornadas do Património, iniciadas em França, em 1983, difundiram-se pelo mundo e hoje, particularmente na sequência das iniciativas da Unesco, assiste-se à universalização do património.

Em Portugal, a Lei 107/2001, de 8 de setembro, que estabelece as bases da política e do regime de proteção e valorização do património cultural, "da maior relevância para a compreensão, permanência e construção da identidade nacional e para a democratização da cultura" (Artigo $1^{\circ}$ ), clarifica os critérios de seleção do que se entende por "bem cultural", revelando uma ideia ampla de património ao referir:

O interesse cultural relevante, designadamente histórico, paleontológico, arqueológico, arquitetónico, linguístico, documental, artístico, etnográfico, científico, social, industrial ou técnico, dos bens que integram o património cultural refletirá valores de memória, antiguidade, autenticidade, originalidade, raridade, singularidade ou exemplaridade. (Artigo $2^{\circ}$, ponto 3, Lei 107/2001, de 8 set.)

Defende, ainda, o acesso do público a esses bens (Artigo 12º como direito fundamental. No entanto, e apesar de alguns avanços normativos, Portugal tem mantido uma postura bastante contraditória relativamente ao património histórico, verificando-se, por vezes, a marca de parâmetros oitocentistas - o património é, muitas vezes, encarado como elemento decorativo, fazendo 'tábua rasa' do passado, ou como sinal de prestígio, mantendo-se uma visão antiquarista, que há muito devia ter sido abandonada, a par de posições que defendem um modelo sustentável de gestão do património. Por outro lado, a legislação é insuficiente para sancionar as depredações patrimoniais e não existem, ainda, políticas concertadas no sentido de desenvolver uma consciência crítica relativamente ao património.

Se é verdade que as referências ao património, à cidade e à cidadania, são hoje uma constante, paradoxalmente, elas correm o risco de deturpar os 
respetivos significados históricos, sociais e culturais, de tal modo se têm vindo a banalizar no discurso político com eco em diversos meios de comunicação social. Por outro lado, se a participação social implica o exercício da cidadania, em muitas situações - por exemplo, em relação aos estudos de impacte ambiental - ela pressupõe um entendimento técnico que a maioria dos cidadãos não possui, sendo essencial um maior cuidado na sua divulgação. A classificação dos bens é um primeiro passo para a sua preservação, mas não é suficiente.

Atualmente, a consolidação do alargamento da noção de património cria, simultaneamente, condições para a expansão dos públicos consumidores de património histórico, resultado do projeto de democratização do saber, herdado do Iluminismo (Choay, 2000) e reanimado pelo desenvolvimento da sociedade de lazer e do turismo cultural, a par da indústria do ócio. Esta preocupação manifesta-se em campos muito diversos, como a reabilitação de centros históricos e a reutilização de edifícios significativos.

Focalizando a reflexão na estrutura espacial dinâmica das cidades, Halbwachs (1990, p.136) salienta que estas se transformaram no curso da História, embora "alguns hábitos locais pareçam resistir às forças transformadoras" e "antigos quarteirões pareçam perpetuar o espetáculo da vida de outrora"; no entanto, duvida que os seus antigos habitantes os reconhecessem se regressassem. Apesar de tudo, considera ser possível "recuperar" o passado porque ele permanece no ambiente material que nos cerca; é a partir desse espaço que o pensamento o pode reconstruir no presente.

As sociedades contemporâneas alargaram de tal forma o conceito de património - material e imaterial, cultural e natural, histórico, arqueológico, artístico, genético... - que este parece referir-se, muitas vezes, a formas de expressão de identidades e de memórias coletivas centradas na continuidade. Defende-se, geralmente, aquilo que se conhece ou o que se valoriza, mas estes dois aspetos nem sempre estão ligados. Esse conhecimento pode não ser experienciado pelos seus habitantes, mas a sua ligação natural ao lugar advém do facto de estarem próximos no espaço, como salientou Halbwachs (1990), pelo que a valorização pode resultar do carácter simbólico atribuído pela comunidade a um património cuja conservação é garantia de continuidade. Os mitos de autenticidade, a visão cristalizada do passado, as representações estereotipadas de diferenças culturais, estão muitas vezes presentes nos debates sobre 
o património e exprimem identidades exclusivistas das sociedades, ao invés de uma necessária, e mais aberta, perspectiva inclusiva e historicizada.

No caso das cidades europeias, o Centro Histórico será o local que melhor revelará a espessura do tempo, ou seja, onde se verifica a sobreposição dos tempos, uma vez que constitui a área mais antiga e, em geral, continuamente ocupada, da urbe. Segundo Choay (2000, p.168), a figura historial da cidade apareceu na obra do italiano Giovannoni, que atribuía valores simultaneamente utilitários e museológicos aos conjuntos urbanos antigos, ao integrá-los numa concepção geral de ordenamento do território. Em 1931, Giovannoni defendia na Carta Italiana del Ristauro a necessidade de proteção do património urbano. Considerava que monumento e conjunto urbano eram realidades que se complementavam e contextualizavam; por isso destacar um monumento era mutilá-lo. Esta abordagem está na origem da chamada "conservação integrada", que só 30 anos mais tarde, na Carta de Veneza, iria ser oficializada. Porém, na sua época interessavam mais as novas e grandes realizações urbanas do que as operações de intervenção no tecido urbano existente. A corrente económico-higienista (caracterizada pelas operações de renovação urbana) e a corrente ideológico-monumentalista (materializada na libertação dos edifícios de exceção) eram as vias mais utilizadas nas intervenções urbanísticas nos centros históricos.

$\mathrm{O}$ interesse pela arquitetura vernacular e pelas técnicas tradicionais de construção, institucionalizado com a publicação da Carta de Veneza em 1964, foi reforçado em 1975, na Carta Europeia do Património Arquitetónico e desenvolvida numa série de Cartas, Declarações e Convenções que se multiplicaram nas décadas de 1970 e 1980. Mais recentemente foram integrados os edifícios industriais, tendo sido a Grã-Bretanha a liderar esse processo de patrimonialização. Na Carta de Veneza consagrara-se, também, o entendimento de Giovannoni relativamente ao património urbano, passando a definir-se o "monumento histórico" como "a criação arquitetónica isolada, assim como o sítio urbano ou rural que transportam o testemunho de uma civilização particular, de uma evolução significativa ou de um acontecimento histórico" (Flores, 1998, p.15). Acrescenta-se à componente memorial, a social, geradora de relações complexas delimitadas por um espaço físico e com o qual interagem. 
Assumir a condição do Centro Histórico como algo que foi transformado e é vivido deve ser condição primordial para a salvaguarda do património, afastando-se de uma ideia de cidade-museu. Sendo resultado da seleção de bens e valores culturais que se tornam propriedade simbólica e real de determinados grupos, o património liga-se a processos de identidade individual e social que contribuem para a diversidade de contextos, pelo que é essencial a sua compreensão.

\section{Consciência Patrimonial e ConsciênCia Histórica}

Assistimos atualmente a uma intensificação do interesse pelo património - visível na ação das mídias, dos museus e sítios históricos, no turismo e no consumo. Até que ponto esse interesse corresponderá a uma consciência patrimonial e, sobretudo, a uma consciência histórica relativamente ao papel dos vestígios patrimoniais na relação temporal?

Segundo Colardelle (1998), três etapas marcam, geralmente, a emergência de um património. A primeira, espontânea, é aquela em que a sociedade produz aquilo que necessita; a segunda é quando há um tomar de consciência que se exerce a favor de uma mutação que ultrapassa o campo utilitário inicial do objeto produzido anteriormente; a terceira, enfim, é aquela em que o objeto conquista uma identidade patrimonial. É na charneira da segunda e terceira etapas que a consciência patrimonial nasce, mas estes tempos têm ritmos aleatórios.

Com ritmos diversos, mas constantemente, as características culturais de todas as sociedades mudam, e as mudanças conduzem fatalmente ao desaparecimento de certos elementos até aí familiares: pessoas, comportamentos, diversos saber-fazer, paisagens construídas ou naturais. É nesses momentos que se poderá produzir a tomada de consciência patrimonial. Colardelle (1998, p.126) salienta que esta "parte de um traumatismo de ruptura é uma reação contra o desaparecimento". Foram sobretudo as acelerações da História contemporânea e da velocidade de propagação da informação, assim como o aumento da esperança de vida, que nos tornaram sensíveis, durante o percurso de vida humana, ao valor patrimonial daquilo que era produzido. As grandes catástrofes, as guerras mundiais e as rápidas mutações tecnológicas suscitaram comportamentos patrimoniais mais imediatos. 
Se muitos edifícios e artefactos foram, ao longo do tempo, adaptados a novos usos, foi o impulso pela preservação, intensificado durante o século XX, que tornou essa adaptação mais consciente. Lowenthal (1999) considera que conhecemos o passado porque lembramos coisas, lemos ou ouvimos histórias e vivemos entre vestígios de tempos anteriores. Os vestígios tangíveis constituem, por isso, pontes essenciais entre o passado e o presente, pois simbolizam laços coletivos ao longo do tempo. Cada ação retém conteúdo residual de outros tempos, mas não podemos evitar refazer o passado, pois "só alterando e acrescentando àquilo que se preserva, se poderá manter real, vivo e compreensível o nosso património" (Lowenthal, 1999, p.411). Por isso, só tomando consciência de que passado e presente não são exclusivos, deixaremos de insistir na preservação de um passado fixo e estável (Lowenthal, 2003).

O processo de constituição de uma consciência patrimonial é, assim, individual e coletivo. Tal como a consciência patrimonial, a consciência histórica é uma construção simbólica e, do mesmo modo que a identidade, comporta um processo de apropriação simbólica do real. Segundo Rüsen (2001), a consciência histórica é estimulada e influenciada pelas experiências do presente, pelo que a sua função de atribuir significado está, em larga medida, dependente do contexto onde é produzida. De acordo com esta análise da consciência histórica, o tempo, à medida que transcorre, provoca pequenas e grandes mudanças que são vividas pelos sujeitos nas suas práticas quotidianas (lebenpraxis): a experiência do tempo e o nosso desejo de prever as mudanças no futuro causam a necessidade de orientação no tempo relativamente à interpretação do passado. A consciência histórica tem, assim, a função de dar à realidade uma orientação temporal, que pode guiar a ação intencionalmente pela mediação da memória histórica. Por sua vez, a História, com as suas normas metodológicas e práticas guiadas pela teoria, pode assumir uma postura crítica em relação aos interesses da vida prática, dado que transcende as particularidades da orientação de senso comum, embora esta também crie o interesse pelo passado.

A orientação temporal na vida e a identidade histórica constituem as duas funções essenciais da consciência histórica (Rüsen, 2001), concretizadas em quatro formas diferentes, com base em quatro princípios de orientação temporal da vida: (a) afirmação de orientações estabelecidas; (b) regularidade de padrões culturais e de vida (Lebensformen); (c) negação; e (d) transformação 
de padrões de orientação. Todos eles surgem pela ação da memória histórica e estruturam os procedimentos para se dar sentido histórico ao passado. A tipologia de consciência histórica proposta por Rüsen (2004) pode fornecer uma estrutura teórica, uma vez que revela os procedimentos da consciência histórica: a consciência de tipo tradicional é a condição dos restantes tipos e, embora não se possa assumir uma sequência estrutural no desenvolvimento da consciência histórica, há um crescimento em complexidade em termos de experiência e de conhecimento do passado, de padrões de significância histórica, e ainda de identidade histórica (do não questionamento da tradição à multiperspectiva do tipo ontogenético). Na vida prática, os modos de consciência histórica tradicional e exemplar são muito mais frequentes que os tipos crítico e ontogenético.

A aprendizagem é, segundo Rüsen (2004), uma qualidade específica dos procedimentos mentais da consciência histórica. A aprendizagem histórica envolve mais do que a simples aquisição de conhecimentos do passado e o seu aumento, características dos currículos tradicionais que se concentravam excessivamente na apresentação da herança nacional aos alunos e tratavam a História como um corpo de informação para ser aceite e memorizada, usando ocasionalmente fontes 'primárias' para estimular a curiosidade ou ilustrar casos particulares. Vista como um processo em que se adquirem progressivamente competências, a aprendizagem de História modifica-se à medida que $\mathrm{o}$ conteúdo da consciência histórica é reconhecido como produto da atividade mental, perdendo o cariz receptivo inicial e assumindo qualidades produtivas. Desta forma, a consciência histórica torna-se uma das categorias chave da didática da História (Rüsen, 2001).

Chapman e Facey (2004) salientam a reflexão sobre três aspetos interconectados - território, identidade e estória - e sobre a forma como situamos a História entre o passado e o presente, pois a literatura sobre consciência histórica refere diferentes modos de relação com o passado e alguns desses modos são mais "históricos" do que outros. Os alunos inferem as suas conclusões acerca das fontes usadas nas aulas, respondendo a questões, mas também colocam as próprias questões, e essas ideias podem ser analisadas em termos de consciência histórica. Tarefas cuidadosamente preparadas pelos professores poderão levantar questões essenciais sobre identidade territorial e estimular os alunos a pensar globalmente, de forma a alargarem os seus horizontes e a 
sua consciência histórica, pois disso depende também a compreensão histórica e a construção de uma identidade inclusiva.

Emmison e Smith (2000) defendem que os objetos e edifícios, assim como as imagens, não devem ser usados de forma meramente ilustrativa, pois carregam significados visuais, sendo também símbolos que usamos para estabelecer identidades. Os objetos estão relacionados com a experiência e atividades quotidianas, por isso, na análise de lugares e espaços, que designam como "dados visuais vividos" (p.152), estes são vistos como contextos espaciais para se compreender os objetos, podendo ser descodificados porque, de certa forma, são textos. Do mesmo modo, Lynch (2008) argumenta que os atributos físicos dos espaços públicos proporcionam sinais e evidências visuais e espaciais que estruturam a sua identidade e articulam-se com aspetos culturais e históricos mais latos: "para ser válido, um espaço público deve ser legível, o que significa que deve ser descodificável pelas pessoas comuns" (p.11). Nesse sentido, Ramos (2004) propõe uma pedagogia pedestre, uma "educação caminhante" (p.46) e salienta a materialidade do passado contida na configuração urbana, assim como contacto com a experiência vivida que pode ser encontrada no mundo dos objetos.

Contudo, ainda se verifica, quer nos programas curriculares quer na prática de sala de aula, um enfoque em fontes escritas e, por vezes, iconográficas. A utilização de fontes patrimoniais em contexto, no ensino de História, não é tão frequente como seria desejável.

\section{Educação Histórica e Patrimonial COM RECURSo A UM CENTRO Histórico}

Praticamente todos os lugares, sejam urbanos ou rurais, industriais ou agrícolas, contêm marcas da atividade humana no passado. Alguns locais revelam vestígios abundantes nos edifícios e estruturas, outros preservam estruturas em uso, embora com funções diferentes das originais, e outros, ainda, exigem técnicas como a prospeção e a escavação arqueológica, pois os vestígios estão escondidos. Neste contexto, a toponímia é crucial para a compreensão dos espaços urbanos antigos, sobretudo quando os vestígios materiais já não são visíveis. É de destacar a toponímia medieval que subsistiu em muitas denominações do espaço urbano, permanecendo no uso comum, revelando uma 
continuidade na ligação ao espaço vivenciado. Constitui, por isso, um elemento patrimonial cuja preservação é crucial para evitar a perda de referências mais remotas, pois o nome contribui para a identidade do lugar.

O património urbano pode revelar as dimensões histórica e cultural de identidades sociais e espaciais. Porém, a apreensão dos seus significados não implica o regresso a uma "pureza" urbana. A mudança faz parte da história humana, dos países ou das cidades, dos edifícios ou dos artefactos. Mas as relações entre preservação e apresentação são complexas. Observam-se, muitas vezes, diferenças na apresentação de sítios e monumentos que perderam o seu uso original, e de edifícios ou lugares com uso contínuo. Devem separar-se estruturas que tiveram uso simultâneo, como as ruínas de um castelo e um centro histórico, ou poderia esse contraste ser devidamente explorado e elucidar sobre alterações verificadas ao longo do tempo?

No Centro Histórico de Guimarães (noroeste de Portugal) - objeto do estudo aqui apresentado - além do Castelo e do Paço dos Duques de Bragança, há um vasto e diversificado património histórico que ultrapassa a dimensão arquitetónica-monumental, e cuja preservação no tecido urbano e social é importante assegurar (Pinto, 2003). A classificação em 2001, pela Unesco, como Património Cultural da Humanidade, associou-lhe uma dimensão universalizante, mas pretender simbolizar uma cultura a partir de fragmentos patrimoniais específicos pode descurar modos de vida e expressões culturais locais cuja historicidade, interpretada de forma apropriada, poderia ser um contributo para a compreensão do passado percecionado através dos seus vestígios e do presente vivido.

Hoje em dia, sempre que deparamos com um nome de rua ou praça que invoque antigos ofícios, tendemos a concluir da sua origem medieval, pois é ideia corrente que nesse período se vulgarizou essa preferência toponímica. Percorrer essa toponímia permite reencontrar atividades quotidianas e aproximar-se ao dinamismo económico, social e cultural das comunidades, pois traduzia o modo como o homem medieval se apropriava do espaço urbano, e seu reconhecimento permite recuperar estruturas espaciais, trabalhos, consumos, crenças e até marcas de ruralidade (Andrade, 1993). Muitas designações toponímicas revelam que grande parte da população urbana se ocupava de atividades artesanais, mas também da venda. Assim, a toponímia permite-nos desenhar a sociologia das ruas. 
Em Guimarães, as ruas Sapateira e dos Mercadores (hoje, rua da Rainha D. Maria II) constituíam o eixo principal de entrada em direção à praça de Santa Maria. Era aí que se encontravam os estabelecimentos mais importantes: alfaiates, ourives, marceneiros, sapateiros. No entanto, era nos arrabaldes próximos que o tratamento dos couros se revelava proeminente. Os nomes das artérias situadas fora de portas mostram a repulsa por determinados ofícios: a rua de Couros era onde se concentravam os que se dedicavam à curtimenta das peles, trabalho demasiado odoroso para ser tolerado no interior do espaço amuralhado (Andrade, 1993). A importância dos curtumes não se manteve apenas ao longo da Idade Média. O tratamento das peles constituiu a marca da identidade deste arrabalde até à atualidade, embora muitos vestígios dessa atividade artesanal tenham desaparecido. Foi nesse arrabalde que se registou o maior incremento industrial, sobretudo ao longo do século XIX, com a construção de edifícios onde os lagares e pelames de granito contrastavam com os pátios e os secadouros, estruturas de madeira com aberturas semelhantes às dos espigueiros. Apesar das más condições de higiene e salubridade, até meados do século XX ainda funcionavam intensamente algumas unidades industriais de curtumes onde se conjugavam práticas ancestrais e alguma atualização técnica. Em 1977, este núcleo industrial foi classificado como de interesse público pela Direção-Geral do Património Cultural e atualmente está em curso o processo de candidatura desta área urbana ao alargamento da classificação 'Património Cultural da Humanidade'.

Muitas designações toponímicas perduraram nos usos e nomeações do espaço urbano, revelando a importância das funções dessas artérias ao longo do tempo. No estudo aqui apresentado, alguns locais como a praça e igreja da Sra. da Oliveira (e o Museu de Alberto Sampaio, no espaço da antiga colegiada da Sra. da Oliveira), a viela de S. Crispim junto à rua da Rainha D. Maria II, a rua de Egas Moniz (antiga Rua Nova do Muro) e a rua de Couros, são integrados em percurso para exploração educativa de fontes patrimoniais por alunos de escolas do município de Guimarães.

Embora a maioria das situações de ensino tenham lugar na sala de aula, algumas, talvez mais produtivas em termos da aprendizagem, realizam-se no exterior, em museus e sítios históricos, ou mesmo no meio envolvente da escola. Reconhecer este potencial é também desafiador para a investigação em Educação Histórica, pois implica que se desenvolvam estudos que atendam à 
forma como os alunos aprendem em diferentes contextos e ao tipo de abordagem mais adequada para desenvolver, por exemplo, a leitura de objetos de museus, edifícios, vestígios arqueológicos, ou narrativas de história oral, sem perder de vista a sua inserção num processo. Nesta perspetiva, a utilização como evidência histórica de fontes patrimoniais ligadas à história local poderá também possibilitar a utilização de metodologias para uma aprendizagem significativa e ultrapassar a ideia de fragmentação dos temas estudados.

É, porém, demasiado simplista a asserção de que a natureza concreta dos materiais históricos ajuda as crianças a descobrirem o passado (Dickinson; Gard; Lee, 1978). O contacto direto com artefactos e edifícios do passado é uma oportunidade para aprofundar conhecimentos sobre pessoas, lugares e acontecimentos, mas deve permitir mais do que isso. Os alunos devem construir a sua interpretação sobre essas fontes históricas, relacionando-as com a sua aprendizagem no momento e os conhecimentos adquiridos ao longo do tempo, mas também é desejável que formulem questões investigativas e hipóteses explicativas acerca do passado de um objeto, edifício ou sítio. Para tal, o trabalho com objetos na sala de aula, nos museus ou outros locais, não se pode confinar a uma sessão, deve ser um processo contínuo. Os alunos precisam de tempo para aprenderem a ler objetos, tal como para ler textos, e conhecer os princípios básicos da sua análise. Desta forma, os alunos não só desenvolvem competências para interpretarem um sítio, edifício ou objeto, mas também as podem aplicar a outros objetos ou locais de interesse histórico.

O uso do património pode ter um importante papel no domínio da Educação Histórica - nas aulas de História, nos projetos, nas visitas de estudo a museus, monumentos e sítios históricos - mas também na sensibilização para a consciência patrimonial e na construção de identidades multifacetadas, pois tudo isto pressupõe a construção de pensamento e consciência históricos, bases para a participação fundamentada e ativa nas comunidades, simultaneamente locais e globais, que caracterizam o presente.

A relação dialógica entre passado e presente (e também o futuro) através dos vestígios do património histórico-cultural ultrapassa as diversas identidades que cada indivíduo conhece durante a sua vida, desde a identidade pessoal e familiar à identidade profissional, ou nacional, ou outra mais ampla. Reconhecendo esta dialética, a análise que aqui propusemos incide em duas dimensões principais: 
- ao nível da Educação Patrimonial, baseia-se no contacto direto com fontes patrimoniais, na defesa de sentidos de responsabilidade em relação ao património histórico e na reflexão crítica e construtiva face às memórias das comunidades com vista à compreensão temporal;

- ao nível da Educação Histórica, assenta na problematização sistemática dos 'usos' da História e do Património, e na elaboração de propostas de desenvolvimento do pensamento histórico de jovens e de abordagens metodológicas dos educadores.

A pesquisa em Educação Histórica, de índole essencialmente qualitativa, tem focalizado não só ideias substantivas mas também ideias sobre a natureza da História, como a de evidência. Recomenda a implementação desde cedo, nas atividades educativas, da exploração de ideias mais elaboradas que o simples repassar de conteúdos, pois a pesquisa tem indicado que crianças e adolescentes revelam modos sofisticados de raciocínio histórico (Barca, 2006) embora a progressão cognitiva não ocorra de forma invariante, determinista e uniforme.

É possível, através da seleção de assuntos que podem ser tratados no âmbito da história local, introduzir de forma interessante e adequada ao currículo de História o uso de fontes patrimoniais, recorrendo, por exemplo, a um museu local especializado ou generalista, ou a sítios históricos próximos da escola (Pinto, 2011). No entanto, experiências didáticas desse tipo ainda são reduzidas, assim como a reflexão sobre o uso do património no projeto curricular das escolas. Embora haja alguns progressos, nem todos os trabalhos assumem um carácter sistemático.

A produção de materiais educativos para a interpretação do património pode fazer-se de modo puramente técnico ou fundamentado numa investigação que defina objetivos, desenvolva modelos, os experimente e avalie. No entanto, há uma diversidade de olhares, de abordagens, que nos dão conta da complexidade patrimonial. Nesse sentido, é essencial conhecer não só que concepções de património revelam os professores e como entendem o uso de fontes patrimoniais nas atividades de ensino, mas também que ideias revelam os seus alunos quando interpretam, em contexto, essas fontes.

Fundamentada na investigação recente em cognição histórica e no âmbito do construtivismo social, a pesquisa em Educação Histórica, que é sobretudo de índole qualitativa, tem afirmado a possibilidade de desenvolvimento da 
noção de temporalidade histórica nos alunos por meio da ação mediadora dos objetos da cultura material, dotados de significado histórico (Nakou, 2003; Cooper, 2004; Cainelli, 2006; Schmidt; Garcia, 2006; Pinto, 2011, 2012, 2015) e do professor. Assim, a realização de atividades relacionadas com o património histórico-cultural de uma comunidade pode favorecer a aprendizagem de conceitos históricos, o que envolve não só a compreensão de situações do passado apresentadas por especialistas, mas também a experimentação de procedimentos metodológicos que permitam aos alunos a interpretação de diferentes fontes históricas (Ashby, 2003; Ashby; Lee; Shemilt, 2005) auxiliando a compreensão da evidência histórica.

\section{ENSINO E APRENDIZAGEM DE História no Centro Histórico de Guimarães}

O estudo empírico aqui apresentado desenvolveu-se no âmbito de uma investigação de doutoramento (Pinto, 2011) que pretendeu aprofundar, numa abordagem sistemática e essencialmente qualitativa (Strauss; Corbin, 1998), a compreensão dos sentidos atribuídos por alunos e professores a fontes patrimoniais, em articulação com conceitos ligados à consciência histórica (Rüsen, 2001) como os de identidade e património. Foi neste contexto multidimensional que se definiu o problema inicial do estudo: De que forma alunos e professores de História interpretam a evidência de um sítio histórico?

\section{Método do estudo}

Através de um estudo descritivo (Pinto, 2011) analisou-se a possibilidade de desenvolver uma atividade de educação histórica e patrimonial no âmbito do currículo de História no $3^{\circ}$ ciclo do ensino básico e no ensino secundário, com recurso a fontes patrimoniais e atendendo à sua relação com a construção de significado acerca do passado. A atividade decorreu no Centro Histórico de Guimarães, com observação de alguns objetos e edifícios situados em locais mais conhecidos como a Praça da Sra. da Oliveira, ou mais ignotos como a Rua de Couros, integrados num percurso com vista à exploração educativa de fontes patrimoniais por alunos -40 de $7^{\circ}$ ano e 47 de $10^{\circ}$ ano, no estudo principal 
- de cinco instituições educativas da cidade de Guimarães (Figuras 1, 2 e 3), no noroeste de Portugal.

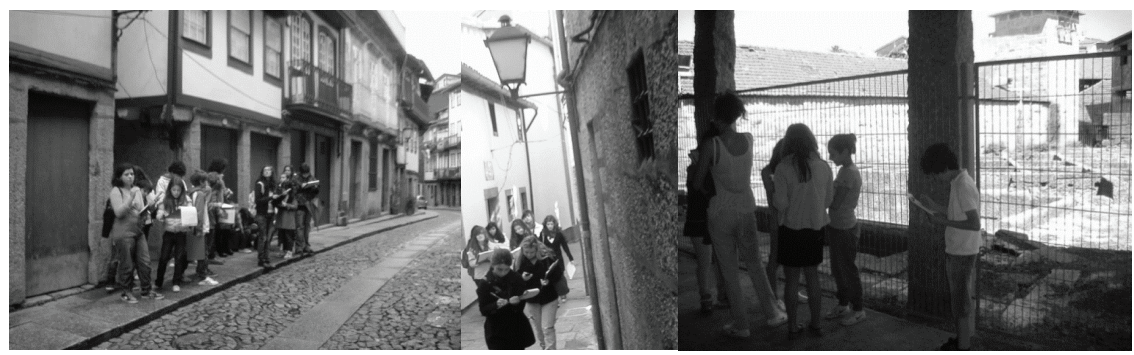

Figuras 1,2 e 3 - Grupos de alunos de $7^{\circ}$ e de $10^{\circ}$ ano realizando a atividade educativa em diferentes pontos do percurso no Centro Histórico de Guimarães, Portugal. (Fonte: a autora).

Os instrumentos de recolha de dados foram o guião-questionário com formato específico para alunos e para professores, e entrevistas de seguimento realizadas a uma parte dos alunos participantes. O guião-questionário para os alunos foi construído de forma a responder a duas questões de investigação: (1) Como usam os alunos de $7^{\circ}$ e de $10^{\circ}$ anos de escolaridade os sítios históricos - espaços, edifícios e objetos com eles relacionados - enquanto evidência de um passado em mudança?; (2) Que tipo de pensamento histórico desenvolvem os alunos em ambiente de exploração direta do património? Por sua vez, o questionário para os professores de História/História da cultura e das Artes teve como principal objetivo a resposta a uma terceira questão de investigação: (3) Que concepções acerca da exploração do património revelam os professores no contexto de atividades sobre uso de fontes patrimoniais, no âmbito do currículo escolar?

O guião-questionário para os alunos (cf. Apêndice) integrava diversas fontes patrimoniais - a observar no local - para cada um dos pontos de paragem de um percurso. Dada a quantidade de fontes patrimoniais (espaços, edifícios ou objetos) passíveis de serem utilizadas, foi necessário fazer uma seleção - própria do método da História - tendo em conta alguma diversidade quanto à tipologia e a articulação entre as fontes observadas, em termos de semelhanças/diferenças quanto a funções e contexto social de produção, além da adequação ao currículo da disciplina. O percurso selecionado atendeu a uma 
lógica curricular, sendo os espaços, edifícios ou objetos observados e interpretados na sua relação com o contexto histórico estudado, nomeadamente pela ligação a personalidades e eventos políticos da história nacional, à organização de poderes e crenças religiosas, ou a funções económicas e sociais significativas no âmbito da história local - microcosmos da história nacional e europeia. Isto permitiria aos alunos terem uma ideia de conjunto e não de objetos isolados, fragmentados ou descontextualizados, mesmo quando já não se encontram no espaço original, como acontece com os objetos observados no Museu de Alberto Sampaio. Daí ter-se integrado, na introdução do guião-questionário, duas figuras representando plantas - uma da antiga vila de Guimarães e outra da cidade atual - onde é assinalada a área a percorrer (cf. Apêndice) e que os alunos observam durante o percurso.

Procurou-se delinear uma abordagem de educação histórica e patrimonial que constituísse um desafio cognitivo genuíno para os alunos. Utilizou-se o mesmo guião-questionário para os alunos do $7^{\circ}$ ano e do $10^{\circ}$ ano de escolaridade, colocando questões que fossem acessíveis e desafiadoras para ambos os grupos, e que permitissem a articulação com conceitos ligados à consciência histórica, nomeadamente os de identidade e património. No conjunto, procurou-se fornecer um mínimo de informação de forma a não determinar as respostas dos alunos. As tarefas propostas em cada um dos pontos do percurso incluíam questões semelhantes, permitindo a comparação das respostas dos alunos em situação de observação de objetos diferentes, e em graus de complexidade crescente dentro de cada conjunto, nomeadamente: "O que podes saber a partir do que observas?", "Que importância teria para os que o construíram? E para ti?", "Gostarias de colocar questões para tentares saber mais sobre este local? Quais?” (cf. Apêndice). Com estas questões pretendia-se obter dados, entre outros, sobre observação e compreensão de materiais utilizados, símbolos de poder, semelhanças/diferenças quanto a funções e contexto social de produção, descrição de mudanças ao longo do tempo, formulação de hipóteses ao refletirem sobre informação disponível, e relação entre história local e história nacional. Assim, os alunos partiriam da informação disponível para a inferência e a colocação de questões acerca das fontes patrimoniais que observavam - essencial para a interpretação das fontes como evidência histórica (Nakou, 2003; Cooper, 2004; Chapman, 2006). Pretendia-se, ainda, conhecer o tipo de consciência histórica, nomeadamente na perspetiva patrimonial, 
revelada pelos alunos na valorização de fontes patrimoniais observadas e na relação dialógica que estabeleciam entre passado e presente.

Relativamente aos professores, quer no questionário prévio quer no questionário posterior à atividade, solicitava-se que respondessem a três questões:

1. [Atendendo ao Currículo...] e perante as fontes históricas/patrimoniais aqui apresentadas, pode referir atividades que se poderiam realizar em contexto de aula de História, com os seus alunos para interpretar os locais/objetos nelas representados?

2. O que pensa que os alunos poderiam aprender com essa(s) atividade(s)?

3. De que forma poderá uma atividade deste tipo ajudar os alunos a inferirem, a partir do património observado, sobre o contexto económico e social medieval?

No segundo questionário, após uma introdução com informações acerca das características da atividade, solicitava-se aos professores que respondessem a três questões após a realização da atividade. Dessas questões, apenas a primeira - 1. Que relação poderá ter, esta atividade, com o currículo da disciplina? - tinha formulação diferente do questionário prévio. O principal objetivo era conhecer as concepções que os professores de História/História da Cultura e das Artes revelavam num contexto de atividades sobre uso e exploração de fontes patrimoniais no âmbito do currículo escolar, acompanhando os respetivos alunos.

\section{Análise de dados}

A análise dos dados contribuiu para solidificar a construção de um modelo conceptual sobre a progressão de inferências históricas de alunos relativamente ao uso da evidência a partir de fontes patrimoniais e dos sentidos atribuídos a essas fontes em termos de orientação temporal e, portanto, em termos de consciência histórica.

Dado que o estudo aqui apresentado se inclui numa investigação de natureza essencialmente qualitativa, inspirada na Grounded Theory (Strauss; Corbin, 1998), procedeu-se a uma análise indutiva dos dados, que foi progressivamente clarificada, aprofundada e sistematizada ao longo das fases do 
estudo (Pinto, 2011), no sentido de identificar perfis conceptuais dos alunos e professores participantes e construir modelos consequentes de tarefas a aplicar em Educação Histórica e Patrimonial.

A análise das respostas dos alunos ao guião-questionário estruturou-se em torno de dois construtos - "Uso da evidência" e "Consciência histórica" - e respetivas subcategorias, em termos de progressão conceptual. Da análise das respostas dos professores aos questionários que lhes foram dirigidos emergiram também dois construtos: "Uso de fontes patrimoniais" e "Finalidades de ensino e divulgação do património", este último organizado em três dimensões, cada uma envolvendo também padrões conceptuais específicos.

Por limitações de espaço e, principalmente, pelo enfoque deste texto no âmbito do ensino de História e da Consciência Histórica, exemplificam-se algumas respostas de alunos e professores participantes no estudo principal quanto a esta categoria conceptual.

Em termos de 'Consciência Histórica', ou seja, quanto ao modo como os alunos deram sentido à relação dialógica entre passado e presente a partir da 'leitura' das fontes patrimoniais, em termos de significância social (compreensão das ações humanas no passado) e de significância pessoal, emergiram cinco níveis de resposta com grau de sofisticação crescente.

No nível menos elaborado - consciência a-histórica - algumas respostas não fazem alusão a qualquer tipo de significância ou apresentam ideias vagas ou estereótipos.

Um grande número de alunos revelou apenas consciência de um passado fixo, pois avaliou as atitudes das pessoas do passado à luz de valores do presente, entendeu o passado em termos genéricos como intemporal e, sobretudo, concebeu o passado à imagem do presente para simples conhecimento, como sugere a resposta da Eva:

- É importante pois este monumento vai-nos transmitir a época e o significado desta batalha. (Eva, $10^{\circ}$ ano, Hist. A, 15 anos, Q. 1.2)

No entanto, diversas respostas expressaram uma consciência de um passado simbólico, entendendo a forma como o património chegou ao presente, e a sua preservação, por seu significado como evocação de acontecimentos chave do passado ou sua simbologia em termos de identidade local e/ou nacional. Algumas respostas indiciaram um uso do passado em relação com um presente emocionalmente simbólico, revelando um sentido de identidade local 
ligado à valorização do património como evocação de acontecimentos de um passado "dourado" que as fontes patrimoniais materializam - em conformidade com uma consciência de tipo tradicional (Rüsen, 2004) e uma consciência de tipo monumental (Seixas; Clark, 2004) - como reflete a Irene, ou à preservação do património como forma de dar continuidade ao passado, referindo-se aos antepassados como modelo ou lição para o presente, o que parece corresponder a uma consciência de tipo exemplar (Rüsen, 2004) ou de tipo antiquário (Seixas; Clark, 2004), exprimindo uma relação emocional entre identidade e património local, como revela a Denise:

- Acho que influenciou porque o artesanato, a escultura, a arquitetura, etc., tem tudo a ver com o nosso passado maravilhoso, e acho que as pessoas olham sempre para o passado. (Irene, $7^{\circ}$ ano, 12 anos, Q. 6)

- O local [curtumes] foi muito bem construído e durou muito tempo, e foi importante para os trabalhadores que nele trabalhavam porque simbolizava a força dos seus antepassados. (Denise, $10^{\circ}$ ano, HCA, 17 anos, Q. 5.2)

Ainda assim, um número significativo de respostas de alunos do $10^{\circ}$ ano, mas também do $7^{\circ}$ ano, revelaram uma consciência histórica emergente, ou seja, uma compreensão da relação passado-presente de forma linear relativamente ao uso e função das fontes patrimoniais e características socioeconómicas associadas ao passado ou ao presente, procedendo já à sua contextualização em termos sociais e económicos, indiciando alguma orientação temporal, como se depreende das respostas da Palmira, da Mara e do Pascoal:

- Importante para a nossa cultura, para estudar a origem da nossa forma de vida, já que este foi o começo do nosso hospital. (Palmira, $7^{\circ}$ ano, 12 anos, Q. 3.2)

- Era importante para os sapateiros pois eram cavidades onde se curtiam as peles para depois serem utilizadas para o trabalho destes. (Mara, 10 ano, HCA, 15 anos, Q. 5.2)

- Os métodos antigos ajudaram a desenvolver novas técnicas e a perceber como eram as suas vidas no passado. Os habitantes podem adquirir conhecimentos culturais sobre a vida em Guimarães. (Pascoal, $7^{\circ}$ ano, 13 anos, Q. 6) 
Por fim, algumas respostas mostraram uma consciência histórica explícita, um sentido relacional entre passado, presente e hipóteses de futuro, utilizando noções de mudança e de permanência como formas de conceptualizar as relações entre os fenómenos em diferentes momentos do tempo, revelando uma consciência da historicidade das fontes patrimoniais, reconhecendo a sua interpretação de forma contextualizada como fundamental para a compreensão histórica e aplicando, nalguns casos, conceitos próprios da metodologia da História. Tiveram em atenção os contextos social, económico, político e cultural em termos de orientação temporal, aproximando-se de uma "consciência de tipo ontogenético" (Rüsen, 2004), como mostram as respostas da Isaura, da Alexandra e da Adelaide:

- Qual era o significado de uma igreja para as gentes desse período, se construíram uma igreja e não um centro comercial? Hoje em dia seria assim. (Isaura, $7^{\circ}$ ano, 12 anos, Q. 1.3)

- Como a população vivia com tais acontecimentos? Quais as dificuldades? O que melhorou depois destes acontecimentos? (Alexandra, 10 ano, Hist. A, 15 anos, Q. 1.3)

- [As peles] Serviam para comércio e provavelmente para sustentar algumas famílias. Devido à carta de foral escrita pelo Conde D. Henrique no século XII. (Adelaide, $10^{\circ}$ ano, Hist. A, 16 anos)

Considerou-se essencial compreender também como os seus professores, mediadores entre as fontes históricas e as interpretações dos alunos, tomam consciência da importância do uso das fontes patrimoniais como evidência, de acordo com critérios metodológicos da História.

No que respeita às "finalidades de ensino e divulgação do património", nomeadamente o modo como os professores de História perspectivam o contributo da exploração de fontes patrimoniais na aprendizagem de História pelos alunos, observou-se, em termos de "Consciência Histórica", que apesar de em alguns casos se verificar uma colagem à informação consultada, a maioria dos professores participantes revelou, em relação ao processo de desenvolvimento do pensamento histórico dos alunos em termos da orientação temporal, uma preocupação com o conhecimento em contexto através de atividades que levam os alunos a inferir sobre o quotidiano e a interligar aspetos sociais, económicos, políticos, religiosos e culturais quando interpretam fontes, 
com vista a uma compreensão contextualizada do passado, como sugere este exemplo:

- Os alunos podem fazer o percurso no Centro Histórico dando especial atenção ao antigo burgo (organização do espaço citadino, os núcleos urbanos nascidos sob a proteção de um castelo e de um mosteiro, os arrabaldes). A organização interior do espaço citadino - onde se encontravam determinados edifícios destinados ao culto divino (catedrais, colegiadas, conventos, etc.), espaços de mercado (açougues, fangas, tendas...), arruamentos por mesteres especializados, bairros onde residiam as minorias religiosas (judiarias e mourarias). A zona amuralhada que fecharia a cidade medieval. (Heliana, prof. $10^{\circ}$ ano, Hist. A, Q. 1)

Apenas algumas respostas permitiram constatar uma relação de tempos em mudança, ao revelarem uma consciência da historicidade das fontes patrimoniais, cuja interpretação permite compreender a complexidade da relação passado-presente em contexto amplo, analisando aspetos políticos, sociais, económicos, culturais, e reconhecendo a diversidade na mudança, como parece propor uma professora:

- Esta atividade proporcionou aos alunos uma análise diferente do contexto da sala de aula, mais interessante, e o contexto do trabalho de grupo promoveu uma dinâmica de observação de algo concreto/real, sobretudo a zona dos curtumes ou "zona de Couros", reconhecendo o contexto económico e social medieval, a multiplicidade temporal, e localizaram no tempo eventos e processos. Reconheceram no seu meio (cidade de Guimarães) as dinâmicas temporais e os diferentes ritmos de evolução desse mesmo meio. (Heloísa, prof. $10^{\circ}$ ano, HCA, Q. 3)

No que respeita à relação identitária com o património, os dados revelaram ideias implícitas de compromisso com uma certa identidade coletiva, mas também ideias indiciando um sentido de identidades múltiplas, características que se aproximam de uma consciência de tipo ontogenético (Rüsen, 2004).

\section{BREVES CONSIDERAÇÕES}

É importante a reflexão sobre a forma como as atividades de exploração de fontes patrimoniais podem modelar as relações entre a disciplina História, o passado histórico e as preocupações do presente. Sendo a aprendizagem histórica uma das dimensões da consciência histórica - como processo mental 
de construção de sentido sobre a experiência do tempo - é importante conhecer como o passado é experienciado e interpretado de modo a melhor compreender o presente e perspetivar o futuro. Mas se a aprendizagem configura as competências de orientação na vida e de construção de identidade histórica, é também influenciada pelo ensino de História.

O modelo conceptual de progressão, por níveis de elaboração, ao permitir conhecer os modos como os alunos exprimem a sua compreensão do passado inferindo a partir de fontes patrimoniais e como tomam consciência da sua orientação temporal (menos ou mais fundamentada historicamente), pode contribuir para uma maior reflexão sobre as formas como os professores podem implementar abordagens mais bem sustentadas do processo de ensino e de aprendizagem significativa e contextualizada. Tais atividades devem envolver a compreensão de situações do passado apresentadas por especialistas, mas também a experimentação de procedimentos metodológicos que ultrapassem as frequentes propostas de materiais educativos em termos prescritivos e impressionistas, e permitam aos alunos a interpretação de diferentes fontes históricas e a realização de inferências com maior complexidade.

$\mathrm{Na}$ sua fundamentação teórica, este tipo de abordagem tem relação intrínseca com o ensino de História, embora isso não signifique uma restrição ao espaço da chamada "educação formal". O uso de fontes patrimoniais - objetos e edifícios individuais ou integrados em sítios históricos - em propostas de tarefas que desafiem as preconcepções dos alunos, e suscitem a sua interpretação em termos de evidência histórica, a par da discussão sobre as ações humanas no passado e sua relação com o presente, poderá ser um contributo consistente para o ensino e a aprendizagem de História, e favorecer a construção de consciência histórica.

\section{REFERENCIAS}

ANDRADE, Amélia A. Conhecer e nomear: a toponímia das cidades medievais portuguesas. A Cidade, Lisboa: Universidade Aberta, p.121-140, 1993.

ASHBY, Rosalyn. O conceito de evidência histórica: exigências curriculares e concepções dos alunos. In: BARCA, Isabel (Org.) Educação histórica e museus. Braga: CIEd, Universidade do Minho, 2003. p.37-57.

.; LEE, Peter; SHEMILT, Denis. Putting principles into practice: teaching and 
planning. In: DONOVAN, M. Suzanne; BRANSFORD, John D. (Eds.) How students learn: History in the classroom. Washington, DC: The National Academies Press, 2005. p.79-178.

BARCA, Isabel. Literacia e consciência histórica. Educar em Revista, número especial, p.93-112, 2006.

CAINELLI, Marlene R. Educação Histórica: perspectivas de aprendizagem da história no ensino fundamental. Educar em Revista, no especial, p.57-72, 2006.

CHAPMAN, Arthur. Asses, archers and assumptions: strategies for improving thinking skills in history in years 9 to 13. Teaching History, n.123, p.6-13, 2006.

.; FACEY, Jane. Placing history: territory, story, identity, and historical consciousness. Teaching History, n.116, p.36-41, 2004.

CHOAY, Françoise. A Alegoria do Património. Lisboa: Edições 70, 2000.

COLARDELLE, Michel. Les acteurs de la constitution du patrimoine: travailleurs, amateurs, professionnels. In: LE GOFF, Jacques (Coord.) Patrimoine et Passions Identitaires. Actes des Entretiens du Patrimoine. Paris: Fayard, 1998. p.123-135.

COOPER, Hilary. O pensamento histórico das crianças. In: BARCA, Isabel (Org.) Para uma Educação Histórica de qualidade. Braga: CIEd, Universidade do Minho, 2004. p.55-74.

DICKINSON, Alaric; GARD, A.; LEE, Peter. Evidence in history and the classroom. In: DICKINSON, Alaric; LEE, Peter (Eds.) History teaching and historical understanding. London: Heinemann, 1978, p.1-20.

EMMISON, Michael; SMITH, Philip. Researching the visual: images, objects, contexts and interactions in social and cultural inquiry. London: Sage, 2000.

FLORES, Joaquim. Património. Do monumento ao território. In: COUCEIRO, João (Coord.) Urbanidade e património. Lisboa: IGAPHE, 1998. p.11-18.

HALBWACHS, Maurice. A memória coletiva. São Paulo: Vértice, 1990.

LE GOFF, Jacques. História e Memória. 2v. Lisboa: Edições 70, 2000.

. (Coord.) Patrimoine et Passions Identitaires. Actes des Entretiens du Patrimoine. Paris: Fayard, 1998.

LOWENTHAL, David. Heritage crusade and the spoils of History. Cambridge: Cambridge University Press, 2003.

. The past is a foreign country. Cambridge: Cambridge University Press, 1999.

LYNCH, Kevin. A imagem da cidade. Lisboa: Edições 70, 2008.

NAKOU, Irene. Exploração do pensamento histórico das crianças em ambiente de museu. In: BARCA, Isabel (Org.) Educação Histórica e Museus. Braga: CIEd, Universidade do Minho, 2003. p.59-82. 
PINTO, H. Educação histórica e patrimonial: conceções de alunos e professores sobre o passado em espaços do presente. Tese (Doutorado em Ciências da Educação Educação em História e Ciências Sociais) - Instituto de Educação, Universidade do Minho. Braga, 2011. Disponível em: http://repositorium.sdum.uminho.pt/ handle/1822/19745; Acesso em: 10 jul. 2012.

. Educação patrimonial e educação histórica: contributos para um diálogo interidentitário na construção de significado sobre o passado. Diálogos, v.19, n.1, p.199-220, 2015. Disponível em: http://www.uem.br/dialogos/index.php?journal= ojs\&page $=$ article\&op $=$ view\&path $\% 5 B \% 5 \mathrm{D}=1049 \&$ path $\% 5 \mathrm{~B} \% 5 \mathrm{D}=$ pdf_713; Acesso em: 1 jun. 2015.

. Guimarães, Centro Histórico: Património e Educação. Dissertação (Mestrado em Património e Turismo) - Instituto de Ciências Sociais, Universidade do Minho. Braga, 2003.

Interpretação de fontes patrimoniais em Educação Histórica. História \& Ensino, Londrina, v.18, n.1, p.187-218, 2012. Disponível em: http://www.uel.br/ revistas/uel/index.php/histensino/article/view/13120; Acesso em: 8 set. 2012.

RAMOS, Francisco Régis L. A danação do objeto: o museu no ensino de história. Chapecó, SC: Argos, 2004.

RÜSEN, J. Historical Consciousness: narrative structure, moral function, and ontogenetic development. In: SEIXAS, Peter (Ed.) Theorizing Historical Consciousness. Toronto: University of Toronto Press, 2004. p.63-85.

. Razão histórica: teoria da história: os fundamentos da ciência histórica. Brasília: Ed. UnB, 2001.

SCHMIDT, Maria Auxiliadora; GARCIA, Tânia Maria Braga. Pesquisas em Educação Histórica: algumas experiências. Educar em Revista, no especial, p.11-31, 2006.

SEIXAS, Peter; CLARK, Penney. Murals as monuments: students' ideas about depictions of civilization in British Columbia. American Journal of Education, v.110, n.2, p.146-171, 2004.

STRAUSS, Anselm; CORBIN, Juliet. Basics of qualitative research: techniques and procedures for developing Grounded Theory. Thousand Oaks: Sage, 1998.

\section{APÊNDICE}

Guião-questionário aplicado aos alunos no estudo principal da investigação, 6 páginas.

Artigo recebido em 29 de março de 2016. Aprovado em 23 de maio de 2016. 

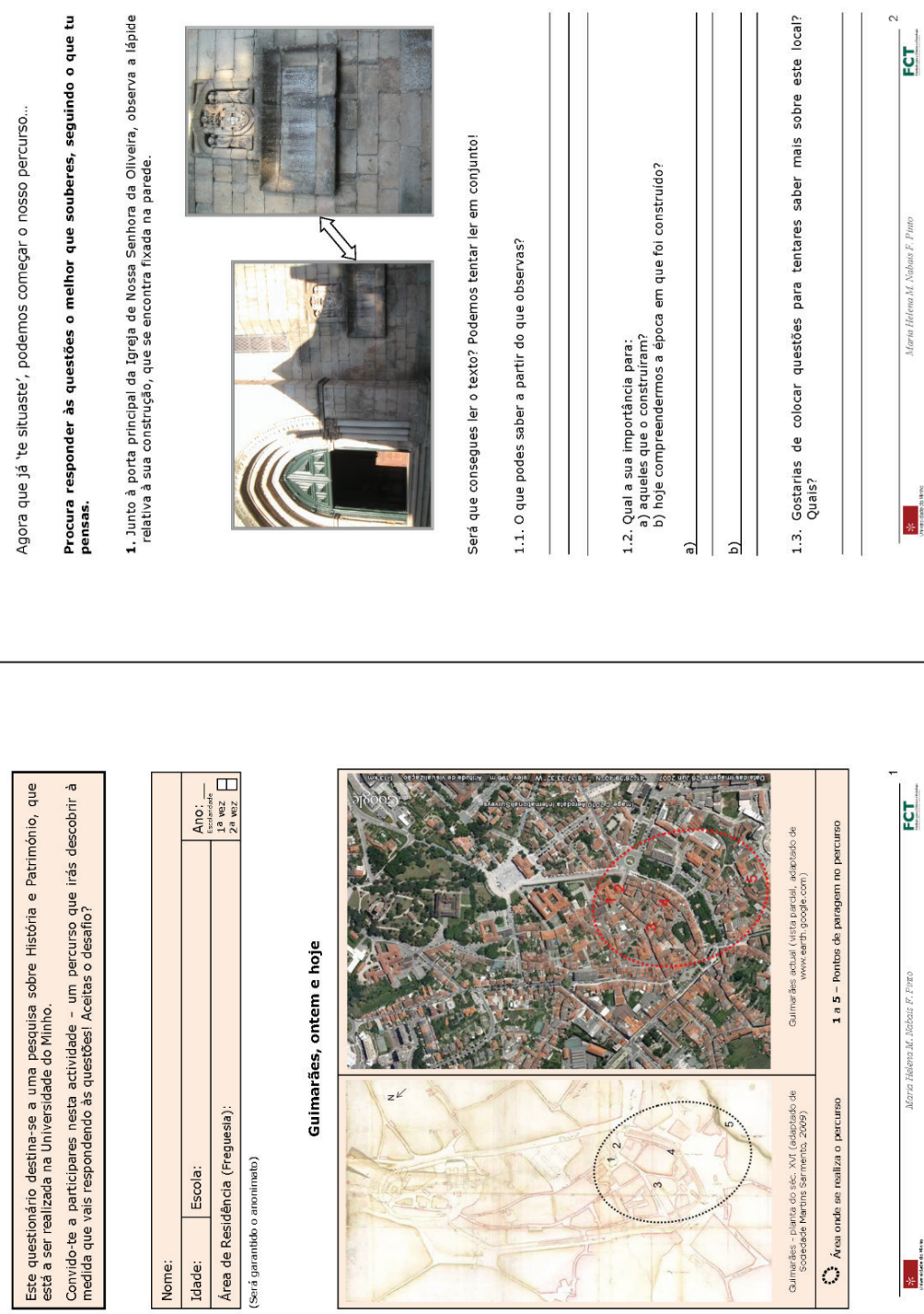

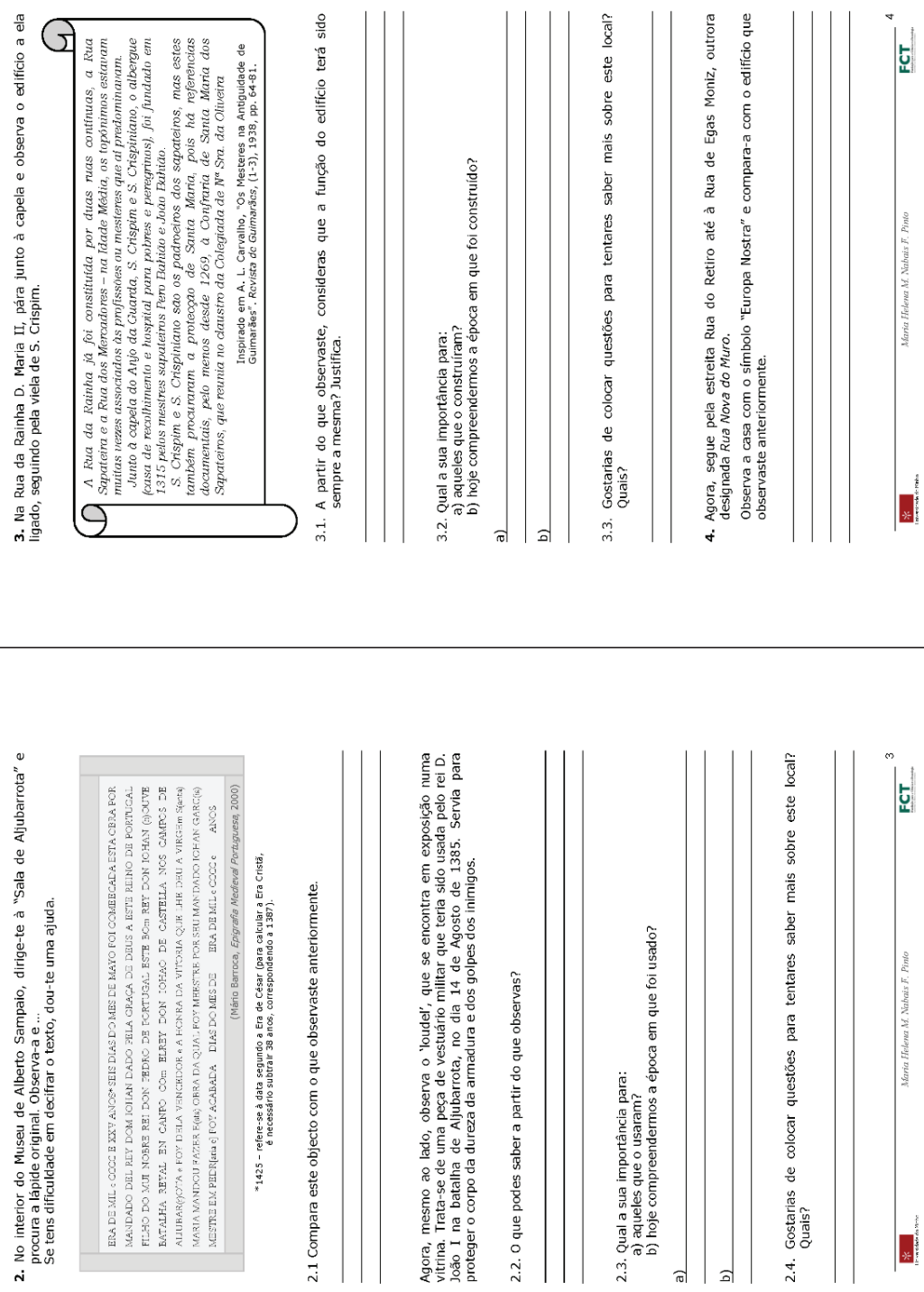

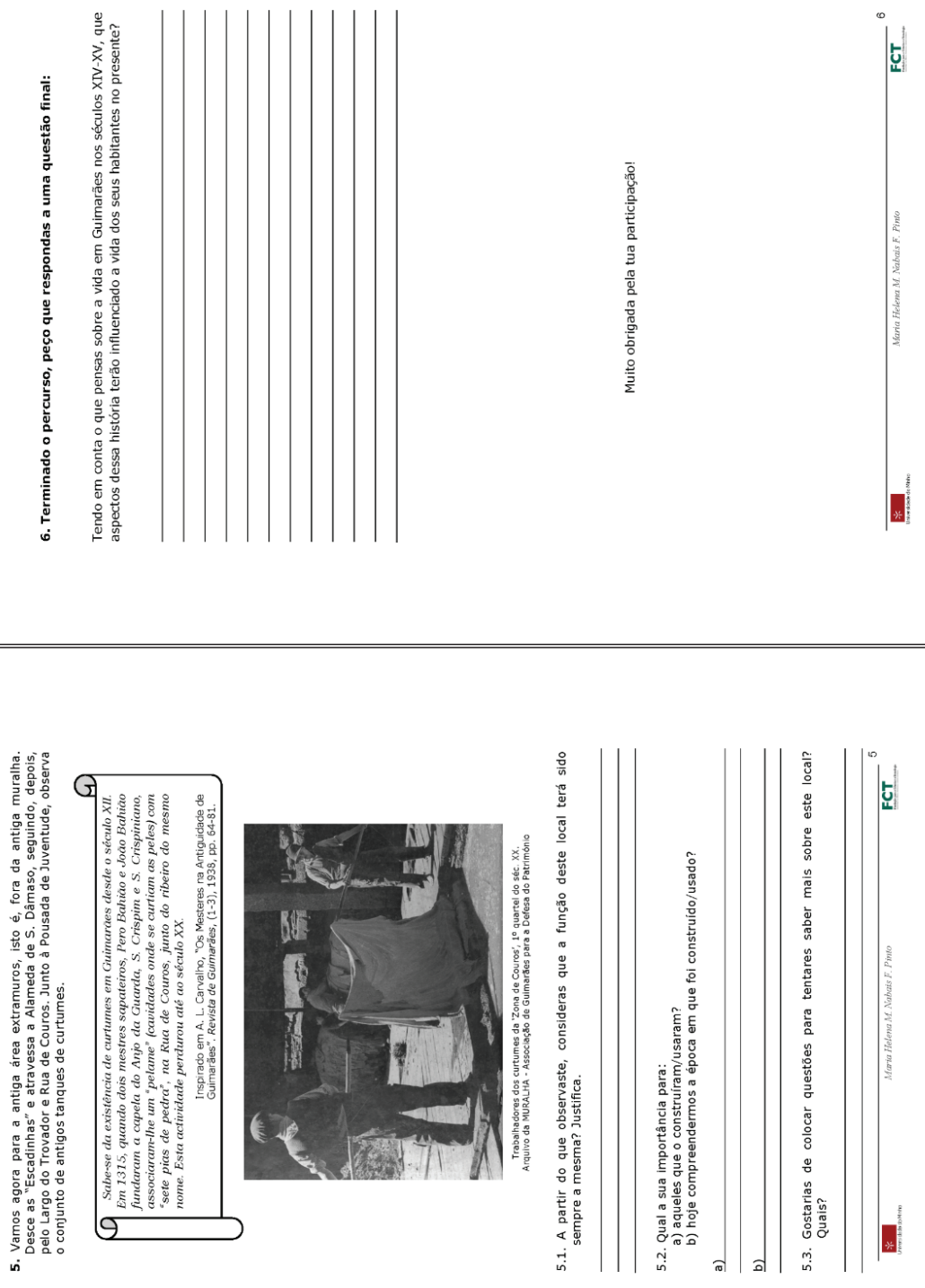